\title{
Tuberous Sclerosis and Astrocytic Hamartoma
}

\section{Yasemin Ozdamar Erol*and Merve İnanç}

Department of Retinal Diseases, Ankara Ulucanlar Eye Education and Research Hospital, Turkey

Corresponding author: Yasemin Ozdamar Erol, Department of Retinal Diseases, Ankara Ulucanlar Eye Education and Research Hospital, Turkey, Tel: +90 31231835 23; Fax: +90 31231248 27; E-mail: yasemin_oz@yahoo.com

Received date: July 4, 2016; Accepted date: July 4, 2016; Published date: July 8, 2016

Citation: Erol YO, İnanç M (2016) Tuberous Sclerosis and Astrocytic Hamartoma. J Eye Cataract Surg 2: 12. doi: 10.21767/2471-8300.100012

Copyright: (c) 2016 Erol YO, et al. This is an open-access article distributed under the terms of the Creative Commons Attribution License, which permits unrestricted use, distribution, and reproduction in any medium, provided the original author and source are credited.

\section{Introduction}

A 21-year-old man presented to our clinic for routine ocular examination. His visual acuity was $20 / 20$ in both eyes. Anterior segment findings and intraocular pressures were unremarkable in both eyes. Fundus examination showed elevated, yellowish and calcified astrocytic hamartoma at the posterior pole in both eye and next to the optic disc in the right eye (Figure 1 and Figure 2). He had fibromas on his face and back (Figure 3 and Figure 4).

The diagnosis of tuberous sclerosis was made early in his life. Ocular involvement occurs in approximately half of patients with tuberous sclerosis. Astrocytic hamartomas of the retina is the fundamental ocular manifestation of tuberous sclerosis. They generally do not grow, but over time some of the lesions may become calcified. Visual loss from retinal and optic nerve hamartomas rarely occurs. Because growth and change of the retinal lesions may seldomly occur, treatment is not indicated.

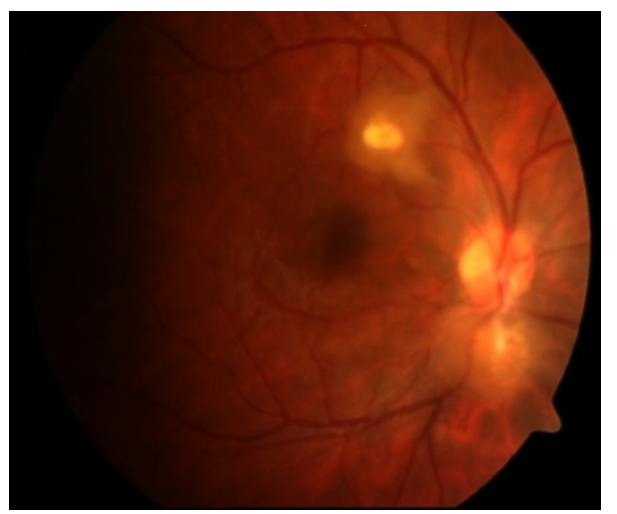

Figure 1: Astrocytic hamartoma at the posterior pole and next to the optic disc in the right eye.

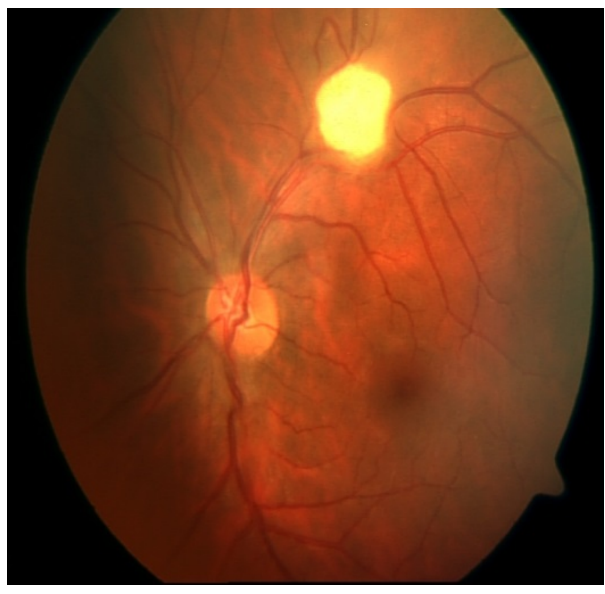

Figure 2: Astrocytic hamartoma at the posterior pole in the left eye.

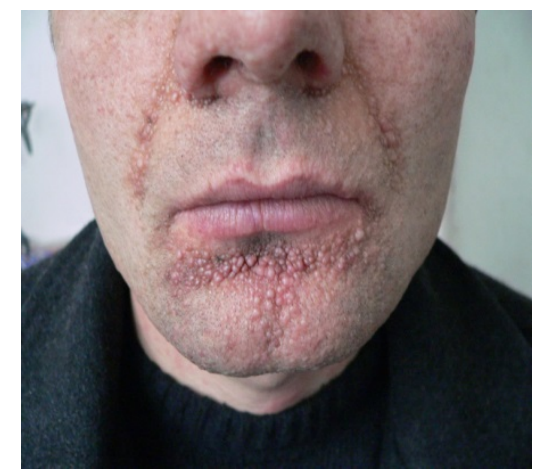

Figure 3: Fibromas on face. 


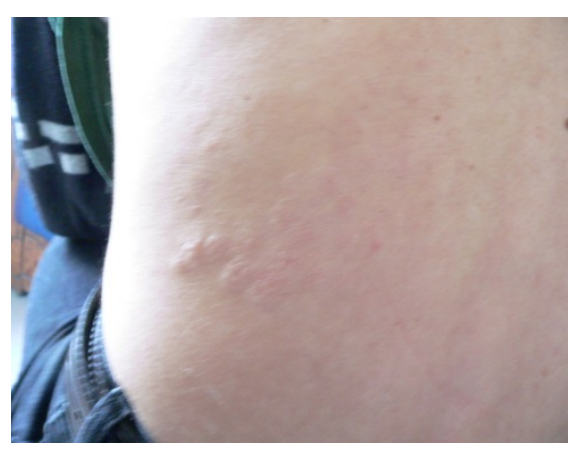

Figure 4: Fibromas on back. 